\title{
The Relation between Canine Hip Dysplasia, Genetic Diversity and Inbreeding by Breed
}

\author{
Frank H. Comhaire \\ Department of Internal Medicine, Ghent University, Ghent, Belgium \\ Email: Frank@comhaire.com
}

Received 18 March 2014; revised 18 April 2014; accepted 28 April 2014

Copyright (C) 2014 by author and Scientific Research Publishing Inc.

This work is licensed under the Creative Commons Attribution International License (CC BY). http://creativecommons.org/licenses/by/4.0/

(c) $\underset{\mathrm{EY}}{\mathrm{B}}$ Open Access

\begin{abstract}
Objectives: To assess the relation between the prevalence of canine hip dysplasia, inbreeding and genetic diversity by breed. Methods: Retrospective pedigree analysis of 9 breeds based on a reference population of 41,728 individuals, and hip dysplasia assessment in 1745 dogs. Results: Hip dysplasia was less common among breeds with higher coefficient of inbreeding, lower genetic diversity, and highest contribution of one single ancestor to the population. Inbreeding not exceeding $3.25 \%$ should be considered safe since it will maintain a sufficiently high genetic diversity within the breed. Clinical Significance: Together with published data on single breeds, the present findings question the general assumption that line-breeding or in-breeding has an adverse effect on the prevalence of hip dysplasia. Hip assessment is indicated in all breeds, but better methods are needed for selecting dogs suitable for reproduction.
\end{abstract}

\section{Keywords}

Genetic Diversity, Effective Population Size, Inbreeding, Hip Dysplasia

\section{Introduction}

A high degree of inbreeding increases the probability of homozygosity of recessive genes, and enhances the risk of hereditary diseases coming to expression. Inbreeding decreases the genetic diversity, and the degree of inbreeding will increase from one generation to the next if genetic diversity is low. However, information is lacking as to the degree of inbreeding that is still safe for healthy breeding.

Canine hip dysplasia (CHD) is related to single nucleotide polymorphisms in a relatively large number of quantitative trait loci [1]. This genetic trait may cause degenerative join disease through multifactorial mechanisms, including inflammation, oxidative overload and, probably, epigenetic changes [2]. It would be expected that the prevalence of CHD by breed should increase if genetic diversity is low, and the degree of inbreeding is 
high. However, this assumption was challenged by generation studies in Golden retrievers [3] [4] and by [5] reporting the prevalence of CHD in German shepherds and Labrador retrievers to increase only if the coefficient of inbreeding is $12.5 \%$ or more.

We were interested in the relation between the prevalence of CHD by breed on one hand, and the coefficient of inbreeding (COI), the level of genetic diversity expressed as effective population size $\left(\mathrm{N}_{\mathrm{e}}\right)$, and the impact of the popular sire effect on the other hand. Also we tried to estimate the degree of inbreeding which would be permissible in order to maintain a sufficient genetic diversity.

\section{Materials and Methods}

The pedigrees of purebred dogs belonging to 23 breeds, that are common in Belgium or belong to the Belgian heritage, were obtained from the database of the Royal Belgian Kennel Club Saint Hubert (Brussels, Belgium). The COI and the $\mathrm{N}_{\mathrm{e}}$ of inbred dogs were calculated using standard formulas [6] [7] by the Research Group on Genetics of domestic Animals of the Catholic University of Louvain, Belgium [8].

In 9 of these breeds hip dysplasia was assessed by the experts of the National Committee for Inherited Skeletal Disorders [9] according to the categorical scoring method recommended by the Fédération Cynologique Internationale (FCI) [10] in the time period between 2006 and 2010. The Norberg angles (NA) are not part of the criteria for classification. The Norberg angles were measured independently by computer assisted image analysis (Digimizer ${ }^{\circledR}$, MedCalc Inc., Ostend, Belgium) as described elsewhere [11]. In short, the computer program allows for the drawing of a circle that perfectly fits the contour of the femoral head. To do so, the cursor is positioned on the cranial aspect of the border of the femoral head and the computer mouse is clicked to define a point on the circle. Next, the cursor is moved to the centre of the femoral head, during which time the monitor displays a flexible circle defined by the first point and the current cursor position. When the circle has been manipulated so that it fits the contour of the femoral head, the mouse is clicked again. At this point, the circle is fixed. In order to measure the NA, the cursor is positioned and the mouse is clicked on the following anatomic landmarks, in sequence: the cranio-lateral aspect of the acetabular rim, the centre of the ipsilateral femoral head, and the centre of the contralateral femoral head.

The reference population of the pedigree analysis of the 9 breeds included 41,728 individuals and the observation period was from 1966 to 2012, and 1745 radiographs were included. Only breeds with at least 21 individuals, and reference population for pedigree analysis exceeding 600 individuals were included (Bouvier des Flandres, Belgian shepherd Tervueren, Belgian shepherd Malinois, Golden retriever, Border collie, German shepherd, Irish setter, Rottweiler, and Labrador retriever).

The CHD average score by breed was calculated by converting the categorical hip scores into numeric values as follows: grade $A=1$ point, grade $B=2$ points, grade $C=3$ points, grade $D=4$ points, and grade $E=5$ points, inspired by "breed value assessment number" [12]. The CHD breed average score is the weighted mean of these numeric values by breed, a higher breed average score corresponding with higher prevalence and/or more severe CHD [13].

The summary characteristics per breed of this group were: $11.6 \%$ (SD: 5.5) of dogs had CHD, the average breed CHD score was 1.65 (SD: 0.24 ), the mean Norberg angle was $104.1^{\circ}$ (SD: $1.81^{\circ}$ ), the average complete generation equivalent was 4.97 (SD: 1.05), the mean coefficient of inbreeding was 3.80 (SD: 1.41), and the mean effective population size $\left(\mathrm{N}_{\mathrm{e}}\right)$ was 82.0 (SD: 23.6).

Statistics included the calculation of means and standard deviations, and of the linear correlation coefficients using the Medcalc ${ }^{\circledR}$ Statistical Programme (MedCalc Inc. Ostend, Belgium) [14].

\section{Results}

Significant positive correlations $(\mathrm{P}<0.01)$ were found between the percentage of dogs with CHD and the CHD breed average score $(r=0.87)$, and between the reciprocal value of the COI and the $\mathrm{N}_{\mathrm{e}}(\mathrm{r}=0.81)$ (Table 1$)$.

Significant negative correlations $(\mathrm{P}<0.01)$ were found between the CHD breed average score and the mean NA $(r=-0.78)$, and between the COI and the $\mathrm{N}_{\mathrm{e}}(\mathrm{r}=-0.85)$. There was a significant negative correlation $(\mathrm{p}<$ $0.05)$ between the highest contribution of one single ancestor and the prevalence of CHD $(\mathrm{r}=-0.75)$ as well as the CHD average score $(r=-0.77)$. Finally, there was a tendency to negative correlation $(\mathrm{P}<0.1)$ between the proportion of dogs with CHD and the mean NA $(r=-0.62)$, and between the COI and the CHD breed average score $(r=-0.57)$. There was no correlation of the complete generation equivalent and any of the other variables. 
Table 1. Correlation coefficient (r-values) and statistical significance (P-values) of the correlation between variables included in the study.

\begin{tabular}{|c|c|c|c|c|c|c|c|}
\hline & $\begin{array}{l}\text { Proportion } \\
\text { CHD }\end{array}$ & $\begin{array}{c}\text { CHD } \\
\text { average } \\
\text { score }\end{array}$ & Mean NA & COI & $\begin{array}{c}\text { Reciproke } \\
\text { of COI }\end{array}$ & $\mathrm{N}_{\mathrm{e}}$ & $\begin{array}{c}\text { Max } \\
\text { contribution } \\
\text { one ancestor }\end{array}$ \\
\hline $\begin{array}{l}\text { Proportion } \\
\text { CHD }\end{array}$ & & $\begin{array}{l}r=0.870 \\
P=0.002\end{array}$ & $\begin{array}{c}r=-0.622 \\
P=0.074\end{array}$ & $\begin{array}{c}r=-0.336 \\
P=0.376\end{array}$ & $\begin{array}{c}r=-0.020 \\
P=0.959\end{array}$ & $\begin{array}{l}r=0.170 \\
P=0.661\end{array}$ & $\begin{array}{c}r=-0.751 \\
P=0.020\end{array}$ \\
\hline $\begin{array}{c}\text { CHD } \\
\text { average } \\
\text { score }\end{array}$ & & & $\begin{array}{c}r=-0.780 \\
P=0.008\end{array}$ & $\begin{array}{c}r=-0.569 \\
P=0.086\end{array}$ & $\begin{array}{l}r=0.327 \\
P=0.356\end{array}$ & $\begin{array}{l}r=0.459 \\
P=0.183\end{array}$ & $\begin{array}{c}r=-0.774 \\
P=0.015\end{array}$ \\
\hline Mean NA & & & & $\begin{array}{l}r=0.270 \\
P=0.441\end{array}$ & $\begin{array}{c}r=-0.280 \\
P=0.433\end{array}$ & $\begin{array}{c}r=-0.480 \\
P=0.189\end{array}$ & $\begin{array}{l}r=0.431 \\
P=0.247\end{array}$ \\
\hline COI & & & & & & $\begin{array}{c}r=-0.848 \\
P<0.01\end{array}$ & $\begin{array}{l}r=0.562 \\
P=0.115\end{array}$ \\
\hline $\begin{array}{c}\text { Reciproke } \\
\text { of COI }\end{array}$ & & & & & & $\begin{array}{l}r=0.810 \\
P<0.01\end{array}$ & $\begin{array}{c}r=-0.438 \\
P=0.238\end{array}$ \\
\hline $\mathrm{N}_{\mathrm{e}}$ & & & & & & & $\begin{array}{c}r=-0.511 \\
P=0.160\end{array}$ \\
\hline
\end{tabular}

Legend to table: CHD: canine hip dysplasia; NA: Norberg angle; COI: coefficient of inbreeding; $\mathrm{N}_{\mathrm{e}}$ : Effective population size; Max contributor one ancestor: maximum contribution of one single ancestor to the breed population.

The COI corresponding with a $\mathrm{N}_{\mathrm{e}}$ of 100 is approximately $3.25 \%$, and the COI corresponding with a $\mathrm{N}_{\mathrm{e}}$ of 50 is approximately $6.5 \%$.

\section{Discussion}

Breeds with a higher proportion of dogs with CHD have a higher CHD breed average score and a lower mean NA. This finding was expected and sustains the validity of the CHD data.

A higher degree of inbreeding was found to correspond with a lower genetic diversity, hence smaller effective population size. The strongest correlation was between the $\mathrm{N}_{\mathrm{e}}$ and the reciprocal value of the COI. These results empirically confirm the mathematical model of population genetics.

It is generally accepted that an effective population size $\left(\mathrm{N}_{\mathrm{e}}\right)$ of 100 is optimal for maintaining a healthy population, whereas any effective population size below 50 will result in increasing inbreeding, which may ultimately lead to extinction of the breed. Based on the strong correlation between the (reciprocal value) of COI and the $\mathrm{N}_{\mathrm{e}}$ it is possible to extrapolate a theoretical limit for safe inbreeding, corresponding with $\mathrm{N}_{\mathrm{e}}$ of 100 , which would be approximately 3.25\%. Inbreeding with COI in excess of $6.5 \%$ should be avoided since it will result in the reduction of the $\mathrm{N}_{\mathrm{e}}$ below the critical value of 50 .

Though the number of breeds included in the present study is small, the findings suggests that a higher degree of inbreeding, and a higher number of single ancestors contributing to the breed population is not associated with an enhanced probability of CHD by breed, rather to the contrary. This confirms the observation by [3] and by [4] using a different approach by analysing individual hip scores of offspring among Golden retrievers in Norway and in the UK. The findings are compatible with those of [5] since the coefficient of inbreeding in the present population was lower than $12.5 \%$.

The inverse relation between inbreeding and CHD is difficult to explain. It may be related to the selection of (popular) sires with good hip quality, but may also be due to the poor heritability of hip dysplasia as estimated by the categorical or semi-quantitative methods recommended by the Orthopedic Foundation for Animals (OFA), the Fédération Cynologique Internationale (FCI), and the British Veterinary Association (BVA) [15] [16]. This is also evidenced by the limited improvement of hip quality seen over the last decades. Better approaches for selecting future breeding animals are urgently warranted [17]. These may include relative breeding values [12], the best linear unbiased prediction method (BLUP, [16] [18], genotyping [1] [19]-[21], quantitative distraction methods [22], and the precise measurement and percentile ranking of the Norberg angle [9].

\section{Conclusion}

The present results empirically confirm the correlation between the coefficient of inbreeding and the effective 
population size, and between the 3 variables assessing the severity of the CHD problem by breed mutually. The finding that a higher degree of inbreeding and lower genetic diversity by breed are not associated with a more severe problem of CHD contrasts with the general belief that line-breeding or in-breeding has an adverse effect in regards to hip dysplasia [4]. Therefore, careful assessment for CHD must be implemented in all breeds, independent of the genetic diversity. Inbreeding with a coefficient not exceeding 3.25\% should be considered safe.

\section{References}

[1] Pfahler, S. and Distl, O. (2012) Identification of Quantitative Trait Loci (QTL) for Canine Hip Dysplasia and Canine Elbow Dysplasia in Bernese Mountain Dogs. PLoS One, 7, e49782. http://dx.doi.org/10.1371/journal.pone.0049782

[2] Glant, T.T., Besenyei, T., Kadar, A., Kurko, J., Tryniszewska, B., Gal, J., Soos, G., Szekanecz, Z., Hoffmann, G., Block, J.A., Katz, R.S., Mikecz, K. and Rauch, T.A. (2013) Differentially Expressed Epigenome Modifiers, Including Aurora Kinases A and B, in Immune Cells in Rheumatoid Arthritis in Humans and Mouse Models. Arthritis Rheum, 65, 1725-1735. http://dx.doi.org/10.1002/art.37986

[3] Lingaas, F. and Klemetsdal, G. (1990) Breeding Values and Genetic Trend for Hip Dysplasia in the Norwegian Golden Retriever Population. Journal of Animal Breeding and Genetics, 107, 437-443. http://dx.doi.org/10.1111/j.1439-0388.1990.tb00055.x

[4] Guth, S. (2009-2010) Hip Dysplasia Stats-What Are They Really Telling Us? NZ Dog World, December 2009/January 2010, 2-3.

[5] Mäki, K., Groen, A.F., Liinamo, A.E. and Ojala, M. (2001) Population Structure, Inbreeding Trend and Their Association with Hip and Elbow Dysplasia in Dogs. Animal Science, 73, 217-228.

[6] Boichard, D. (2002) Pedig: A Fortran Package for Pedigree Analysis Suited to Large Populations. 7th World Congress on Genetics Applied to Livestock Production, Montpellier, 19-23 August 2002, 28-13.

[7] Meuwissen, T. and Luo, Z. (1992) Computing Inbreeding Coefficients in Large Populations. Genetics Selection Evolution, 24, 305-313. http://dx.doi.org/10.1186/1297-9686-24-4-305

[8] Wijnrocx, K., Janssens, S. and Buys, N. (2012) Inteelt en Genetische Diversiteit van 23 Populaties van Honden in België op Basis van Afstammingsgegevens van de KMSH, 41. https://lirias.kuleuven.be/bitstream/123456789/358026/3/RapportInteeltGenetischeDiversiteitHondenBelgië.pdf

[9] Comhaire, F. and Schoonjans, F. (2011) Canine Hip Dysplasia: The Significance of the Norberg Angle for Healthy Breeding. Journal of Small Animal Practice, 52, 536-542. http://dx.doi.org/10.1111/j.1748-5827.2011.01105.x

[10] Flückiger, M. (2007) Scoring Radiographs for Canine Hip Dysplasia-The Big Three Organisations in the World. European Journal of Compagnion Animal Practice, 2, 135-140.

[11] Comhaire, F.H., Criel, A.C., Dassy, C.A., Guévar, P.G. and Snaps, F.R. (2009) Precision, Reproducibility, and Clinical Usefulness of Measuring the Norberg Angle by Means of Computerized Image Analysis. American Journal of Veterinary Research, 70, 228-235. http://dx.doi.org/10.2460/ajvr.70.2.228

[12] Beuing, R. (2000) Zuchtwertschätzung in der Hundezucht. Golden Retriever, 62, 33-35.

[13] Comhaire, F. (2013) Understanding Canine Hip Dysplasia. LAP Lambert Academic Publishing, Saarbrücken.

[14] Schoonjans, F., Zalata, A., Depuydt, C.E. and Comhaire, F. (1995) MedCalc: A New Computer Program for Medical Statistics. Computer Methods and Programs in Biomedicine, 48, 257-262. http://dx.doi.org/10.1016/0169-2607(95)01703-8

[15] Hou, Y., Wang, Y., Lust, G., Zhu, L., Zhang, Z. and Todhunter, R.J. (2010) Retrospective Analysis for Genetic Improvement of Hip Joints of Cohort Labrador Retrievers in the United States: 1970-2007. PLoS One, 5, e9410. http://dx.doi.org/10.1371/journal.pone.0009410

[16] Malm, S., Sorensen, A.C., Fikse, W.F. and Strandberg, E. (2013) Efficient Selection against Categorically Scored Hip Dysplasia in Dogs Possible Using Best Linear Unbiased Prediction and Optimum Contribution Selection: A Simulation Study. Journal of Animal Breeding and Genetics, 130, 154-164. http://dx.doi.org/10.1111/j.1439-0388.2012.01013.x

[17] Hartmann, P., Stock, K.F. and Distl, O. (2012) Multivariate Prediction of Breeding Values for Canine Hip and Elbow Dysplasia as Well as Humeral Osteochondrosis in the Bermese Mountain Dog. Berl Munch Tierarztl Wochenschr, 125, 432-440.

[18] Janutta, V., Kamann, H. and Distl, O. (2008) Genetic and Phenotypic Trends in Canine Hip Dysplasia in the German Population of German Shepherd Dogs. Berl Munch Tierarztl Wochenschr, 121, 102-109.

[19] Stock, K.F., Klein, S., Tellhelm, B. and Distl, O. (2011) Genetic Analysis of Elbow and Hip Dysplasia in German Shepherd Dog. Journal of Animal Breeding and Genetics, 128, 219-229.

http://dx.doi.org/10.1111/j.1439-0388.2010.00901.x 
[20] Guo, G., Zhou, Z., Wang, Y., Zhao, K., Zhu, L., Lust, G., Hunter, L., Friedenberg, S., Li, J., Zhang, Y., Harris, S., Jones, P., Sandler, J., Krotscheck, U., Todhunter, R. and Zhang, Z. (2011) Canine Hip Dysplasia Is Predictable by Genotyping. Osteoarthritis Cartilage, 19, 420-429. http://dx.doi.org/10.1016/j.joca.2010.12.011

[21] Hou, Y., Wang, Y., Lu, X., Zhang, X., Zhao, Q., Todhunter, R.J. and Zhang, Z. (2013) Monitoring Hip and Elbow Dysplasia Achieved Modest Genetic Improvement of 74 Dog Breeds over 40 Years in USA. PLoS One, 8, e76390.

[22] Powers, M.Y., Karbe, G.T., Gregor, T.P., McKelvie, P., Culp, W.T., Fordyce, H.H. and Smith, G.K. (2010) Evaluation of the Relationship between Orthopedic Foundation for Animals' Hip Joint Scores and the PennHIP Distraction Index Values in Dogs. Journal of the American Veterinary Medical Association, 237, 532-541.

http://dx.doi.org/10.2460/javma.237.5.532 